\title{
Emotional Design of Educational Animations: Effects on Emotion, Learning, Motivation and Interest
}

\author{
Ali Haydar Bülbül * \\ Department of Computer Education and Instructional Technologies, Anadolu University, \\ Eskişehir, Turkey \\ ORCID: 0000-0002-0116-8070
}

\begin{abstract}
Abdullah Kuzu
Department of Management Information Systems, İmir Demokrasi University, İzmir, Turkey ORCID: 0000-0002-1030-0424
\end{abstract}

\begin{tabular}{ll}
\hline \hline Article history & This study aims to investigate the effect of different formats of \\
Received: & emotionally designed educational animations in terms of the emotional \\
08.12 .2020 & worthiness of the material, retention and transfer, intrinsic motivation, \\
Received in revised form: & subject interest and cognitive load. In this direction, an experimental \\
14.02 .2020 & research approach was adopted. Five emotionally diverged animations \\
& were developed for the study, one of which was designed without adding \\
Accepted: & any appealing illustrations. Animations were about the life cycle of low \\
18.02 .2021 & mass stars and was developed by researchers under the supervision of an \\
Key words: & animation expert. With one control and four treatment groups, \\
\hline Emotional design; & experiment was carried out with the participation of 256 students at a \\
Intrinsic motivation; & state university in Turkey. Data were gathered using Turkish adaptation \\
Interest & of Subject Interest Scale, Intrinsic Motivation Scale, one-item Subjective \\
& Cognitive Load Scale, and a retention test, a transfer tests and an \\
emotional experience survey which were developed by the researchers. & Turkish adaptation process of Subject Interest Scale and Intrinsic \\
Motivation Scale were also conducted by the researchers. Findings \\
showed that two of the animations, both of which included character \\
animations and one of which was enhanced by an introduction music and \\
emotionally complementary sound effects, were emotionally effective. \\
According to the results, emotionally effective animations had positive \\
effects on transfer, intrinsic motivation and subject interest while no \\
effect was found in terms of retention and cognitive load.
\end{tabular}

\section{Introduction}

We live in an era that almost all information travels through information and communication technologies. Today, it is very likely to access any information in any multimedia format via simple internet search. Not to mention, there are both reliable and unreliable resources in forms of appealing or less appealing multimedia, which might

\footnotetext{
${ }^{*}$ Correspondency: alihaydarbulbul@anadolu.edu.tr
} 
determine users' tendencies to choose these as primary sources. Today's society, the so-called post-truth society, tend to prefer and trust resources they feel emotionally close so much that they might even ignore the facts (Rider \& Peters, 2018). This might be considered to be a distracting factor from an educational perspective; however, it can also provide educators with a variety of instruments that enhance teaching and learning process, considering the role of emotions on cognition, motivation and learning.

Various approaches to emotions predict that emotions are important factors or determinants of certain behaviors. Darwin (1872) interprets emotions as evolved functions that help species survive by leading them how to behave when they face certain incidents. It is suggested that what we do is a result of an internal evaluation, which is also affected by interest, enjoyment and satisfaction (Sansone \& Harackiewicz). Motivation, which is a term to refer to whilst considering what and why we do things, is a complicated phenomenon and depends on affective and cognitive processes, such as thoughts, beliefs and emotions, and it can be also affected by social factors (Schunk, Meece \& Pintrich, 2014). Emotions have an important effect on intrinsic, extrinsic and social motivation (Pekrun, 1992). As Kim and Hogges (2012) suggested, positive emotions, such as enjoyment and satisfaction, lead to higher levels of intrinsic motivation, while negative emotions, such as anxiety, boredom and sadness, cause lower level of intrinsic motivation and increase negative intrinsic motivation.

Arnold (1960), with a cognitive perspective, suggests that thoughts and emotions are inseparable phenomena and that emotions come to existence in the form of either positive or negative reactions towards an incident, as a result of internal evaluations of individuals, which is determined by their background, personality and psychology. As Pekrun (1992) reports, information is transferred to memory together with the emotions experienced while being exposed to information. Likewise, Stein and Levine (1991) report that emotions are almost always activated in order to make sense of the incoming information. Thus, emotions help activate knowledge in the long term memory, and so, help recall it (Pekrun, 1992). Besides, Hertel et al. (2000) indicated that emotions have an effect on decision making and cooperation.

Literature also suggests a reciprocal connection between learning and emotion, emotion being the catalyzer for rational thinking (Felten, Gilchirst, \& Darby, 2006). Learning occurs as a result of a holistic process of thinking, feeling, perceiving and behavior (Kolb, 1984). In this manner, learners need emotional support when they experience new tasks and new study environments (Eyler \& Giles, 1999). Pekrun (2002) emphasized the reciprocal relationship of motivation and cognition, explaining the effect of emotions on learning, and suggested that positive emotions enhanced learning while negative emotions had an effect on learning negatively in short term but might have a positive effect in longer term.

For a long period of time, multimedia learning research focused particularly on cognitive approaches. Predictions of cognitive load theory (Sweller, 2005) and cognitive theory of multimedia learning (Mayer, 2009) have been the leading theoretical frameworks multimedia research are based on. In this time period, emotional aspects were mostly ignored. Cognitive theory of multimedia learning (CTML) even predicted that interesting but irrelevant illustrations would distract learning (Mayer, 2009). Recently, however, emotional aspects were also begun to be considered in multimedia research and reported inconsistent results with CTML. Cognitive-affective Theory of Learning Media (CATLM), which is an extension of CTML, predicts that motivation and affective processes of an individual have an influence on selecting incoming information and transferring them to working memory (Moreno, 2006). 
Several evidence-based research, most of which were based on the predictions of Moreno's CATLM, reveals that appealing and decorative illustrations, such as appealing -or warmcolors, rounded or -baby-face-like- shapes, personified -or anthropomorphic- shapes did not increase extraneous processing, on the contrary, they fostered learning, motivation and situational interest (Königschulte, 2015; Magner et al., 2013; Mayer \& Estrella, 2014; Park et al, 20145; Plass et al.,2014; Um et al, 2011).

Um et al. (2011) revealed that multimedia learning materials, which are designed with warm colors, rounded and anthropomorphic shapes, helped participants maintain their positive mood and changed participants' neutral moods into positive mood. They also reported that participants who were exposed to emotionally designed materials were more successful in comprehension and transfer tests, and had higher levels of motivation while cognitive load levels did not differ. In a replication study, Plass et al. (2014) also found consistent results except that they were not able to prove the effect of emotional design on transfer test and failed to show the positive effect on participants' moods in one of their experiments. In another replication study, however, Park et al. (2015) failed to find significant differences in terms of comprehension, transfer, motivation, cognitive load and situational interest. On the other hand, Magner et al. (2013) revealed that using decorative illustrations led higher levels of situational interest while no significant difference was found in terms of learning. Königschulte (2015), used background sounds for emotional design and found no effect of emotional design on either learning or cognitive load, while reporting higher level of motivations for emotional design group. Mayer and Estrella (2014) used appealing colors, rounded shapes and personification in their emotional designs and reported that emotionally designed materials led higher learning achievements (both comprehension and transfer) and higher levels of motivation, with respect to those designed based on multimedia learning principles. However, their first experiment revealed higher cognitive load in emotional design group, while second experiment showed no difference.

This research, on the basis of CATLM, seeks further findings about the effect of emotional design on emotion induction, learning, intrinsic motivation, subject interest and cognitive load. Distinctively from previous research, this study emphasizes on educational animations, and puts emotional worthiness of the material designs at the center by practicing different formats of emotionally designed animations, exercising 12 principles of animations (Thomas \& Johnston, 1981) and the findings of preliminary qualitative research of the authors on the emotional design issues of multimedia learning materials (Bülbül \& Kuzu, 2019). 12 principles of animations are the techniques that were emerged from the fifty-year-experience of Walt Disney animators, as Thomas and Johnston reports, and that made Disney a pioneer and a legend in animation field (1981). These principles, which are "squash and stretch, anticipation, staging, straight ahead action and pose to pose, follow through and overlapping action, slow in and slow out, arcs, secondary action, timing, exaggeration, solid drawing and appeal", essentially intend to create believable characters and worlds and so, establish an emotional connection with audience (Thomas \& Johnston, 1981). In this manner, it is considered that these artistic principles might serve for emotional design of multimedia learning materials. In accordance with the literature, this study aims to investigate the effects of different formats of emotional designs in terms of emotional worthiness of the emotional designs, learning, intrinsic motivation, subject interest and cognitive load. 


\section{Method}

\section{Research Design}

This study aims to investigate the effect of emotional design on learning, motivation, subject interest and cognitive load. In accordance with this aim, the study adopted randomized post-test-only control group and randomized pre-test post-test control group designs depending on the outcome variables. In this experimental study, one control group received an animation designed in line with multimedia principles, and four treatment groups each received a different format of emotionally designed animation. Retention test scores, transfer test scores, motivation levels, level of emotional experience points and cognitive load levels were identified as the dependent variables of the randomized post-test-only control group design, and subject interest pre-test scores were used as covariant variable for motivation. Pre-test and post-test scores of subject interests, on the other hand, were the dependent variables of randomized pre-test post-test control group design.

\section{Participants}

311 School of Education/Faculty of Education students at a Turkish state university voluntarily participated in the study. Students with no pre-knowledge of the subject matter were sought and participants who did well in pre-knowledge test were not included in the study. Participants were randomly assigned to control and treatment groups. After the exclusion of these participants and the data cleaning, the analysis was carried out with the data of 256 participants (f:132, m:124) in total.

\section{Study Materials}

Study materials used in the study were computer-based animations that explained the life cycle of low mass stars. The animations did not differ in terms of the content or the narration. In order to be used in control and treatment groups of the experiment, five different animations were developed by the researchers. The design and development process of the study materials were carried out with the support of two animation experts, two subject area experts and one multimedia design expert. The content of the materials was determined by the researchers and a draft was prepared. The draft was refined in accordance with the feedback of an academician studying astrophysics and the construct of the main content of the animations were determined. After determining the content, the researchers prepared the storyboards for each format, working together with an animation expert. Based upon the storyboards, animations were developed by researchers with technical and procedural support of the animation expert, using MOHO Anime Studio and Adobe After Effects software. The narrator was an amateur radiobroadcaster who had a clear voice and good diction. At the end of the development process, animations were introduced to one subject area expert, one animation expert and one multimedia design expert. The designs were refined according to the feedback, and five animations, each lasting 4 minutes and 43 seconds, were put into final forms.

Study materials differed by emotional design issues and were ensured not to differ by means of any other confounding variable, consulting a multimedia design expert. Except the one that was presented to the control group, all other animations were designed implying several emotional elements, which are explained in detail below.

Basic multimedia design $(C)$ : This animation, which was designed for control group of the 
experiment, was developed purely based on the multimedia principles (Mayer, 2009). Avoiding any decorative and appealing design elements, grayscale tones and cornered shapes were used for the design of visuals. Sample screenshots of the animation can be seen at Figure 1.

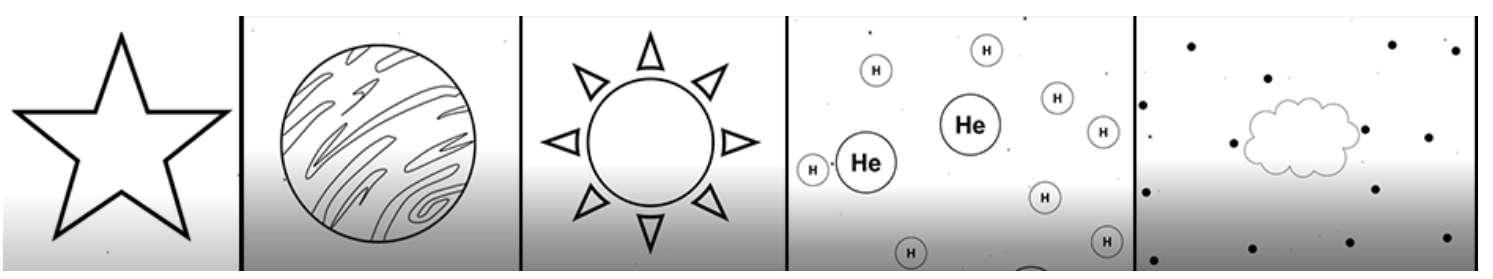

Figure 1. Sample screenshots of basic multimedia design

Basic emotional design (T1): In this design format, emotional elements that were suggested in the literature, such as colors, rounded shapes and personification, were implied. Mostly warm colors were preferred and basic lines were drawn on the shapes to illustrate a simple smiling face. This format is intentionally developed as an unsuccessful implementation of emotional design. Sample screenshots of this animation are shown at Figure 2.

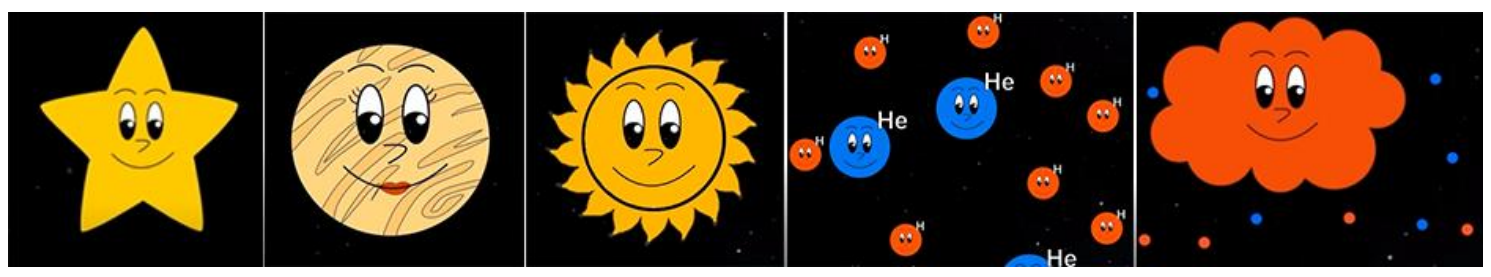

Figure 2. Sample screenshots of basic emotional design

Emotional design with enhanced visuals (T2): In this design, similar to the basic emotional design format, colors, rounded shapes and personification elements were used. Distinctively, the visuals were more appealing in terms of colors and shapes, with shadings and depth, and each object in the animation was personified with contextual human-like characteristics, such as; planet Jupiter was illustrated as a king, planet Venus as an attractive woman, Nebula as a resting cloud, Protostar as a baby on a fluffy cloud and with a baby bottle, Main Sequence Star as a young man with a beard and a piercing, helium atom as a noble person, Red Giant as a big angry monster, White Dwarf as an old man and so on. Still, these visuals remained static throughout the animation. Sample screenshots can be seen at Figure 3.

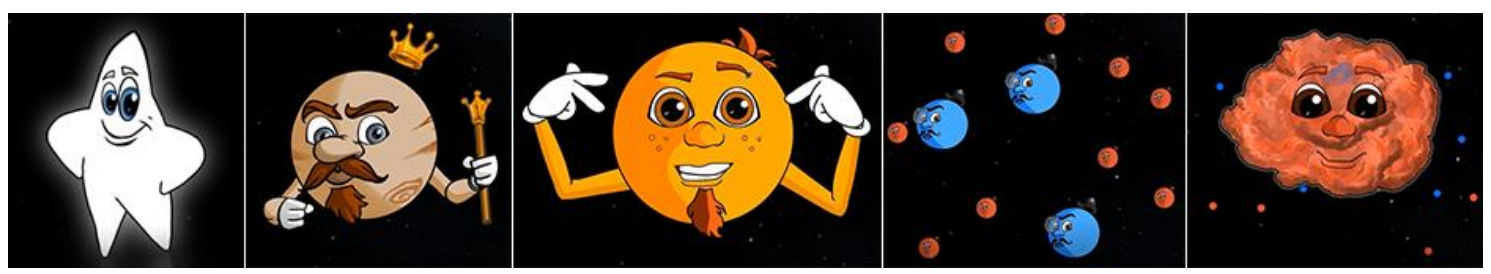

Figure 3. Sample screenshots of emotional design with enhanced visuals

Emotional design with character animations (T3): In this design, visual forms were very similar to the ones in emotional design with enhanced visuals. However, the main concern designing this animation was to create believable and emotionally connectible characters, which could enable emotional transfer. In this direction, various emotionally supportive elements were included in the animation, which are based on 12 principles of animation 
(Thomas \& Johnston, 1981) and on the findings of the preliminary qualitative inquiry of the authors (Bülbül \& Kuzu, 2019). These emotional elements were, in brief, as part of the personification process enabled by assigning contextual and human-like attributes to the characters, appealing mimics and jests, fluent motions, exaggerated emotional expressions, as well as adding references to real life events, cinematographic tools and so on (Bülbül \& Kuzu, 2019). To give examples, the star on the introduction scene was winking at the audience, Jupiter was hitting on the ground with his scepter, Venus was playing her hair looking at the mirror, the sun (main sequence star) was bored of waiting for millions of years yawning and looking at his watch, Nebula was tucking away the particles around, red giant was a red hot and was roaring, white dwarf was at the death's door and was coughing, also the camera zoomed in and out of the characters to show what was happening inside, and throughout the animation, a star was born, grew older and died eventually. Sample screenshots of this animation are shown at Figure 4.

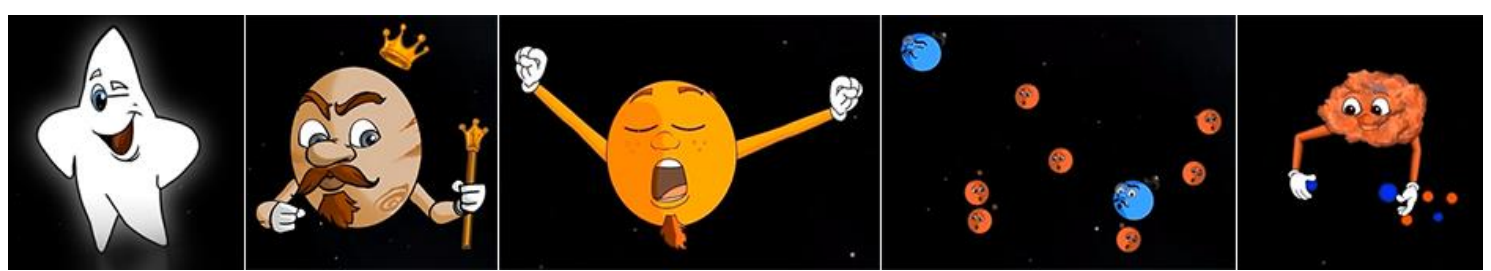

Figure 4. Sample screenshots of emotional design with character animations

Emotional design with character animations and sound effects (T4): In this animation, visual design was exactly the same with the previous format (T3), except that this animation was enhanced with an introduction music and complementary sound effects in order to enhance the believability of the movements in the animation.

\section{Data Collection Tools}

In this experiment, subject interest, intrinsic motivation, cognitive load, retention and transfer, and emotional experience were identified as variables. Subject interest was measured by Subject Interest Scale which was a four level Likert type questionnaire consisting of four items. The original scale was suggested by Schaffner \& Schiefele (2007) and was adapted to Turkish and to the subject area by the authors ptior to the current study. Confirmatory factor analysis indicated good fit ( $\chi 2 /$ df:1.35; RMSEA:0.04; SRMR:0.02; CFI:0.99; GFI:0.99; NFI:0.99). Intrinsic motivation was measured by Intrinsic Motivation Scale that was suggested by Isen \& Reeve (2005). The original scale included eight items in form of seven level Likert type questions. The scale was adapted to Turkish by the authors previously from the study. Because, confirmatory factor analysis did not reveal acceptable fit, items were reviewed through modification suggestions, and two couple of items were considered to have the likelihood of being identified in a very similar fashion by the participants. After modifications, results showed acceptable fit ( $\chi 2 / \mathrm{df}: 2.44$; RMSEA:0.09; SRMR:0.03; CFI:0.98; GFI:0.94; NFI:0.97). For the measure of cognitive load, one item subjective cognitive load scale was used. The scale was suggested by Paas \& van Merrienboer (1993) and adapted to Turkish by Kilıç \& Karadeniz (2004). Retention and transfer tests were prepared by the researchers together with the subject area expert. Retention test consisted of seven multiple choice questions while transfer test included one multiple choice and four open-ended questions. Emotional experience variable was included in order to understand the emotional values of the animations developed. In this direction, participants were asked to 
evaluate the emotional level they experienced watching the animation with a Likert type question ranging between very negative and very positive.

\section{Data Analysis}

Data was analyzed through comparison tests, animation format being the categorical variable. The dataset did not satisfy the premises of multivariate analysis of variance and each outcome variable was analyzed separately. Because interest is considered as an important mediator of motivation, pre-test scores of subject interests were used as the covariant variable in the comparison tests of intrinsic motivation. So, intrinsic motivation levels were analyzed using one-way ANCOVA; while retention test scores, transfer test scores, and cognitive load levels were analyzed using one-way ANOVA. Besides, emotional experience points were interpreted through descriptive statistics and one-way ANOVA. In order to test the effect of each animation on subject interest, each group was separately analyzed using paired-samples t-test.

\section{Procedure}

The experiment was carried out in the computer labs of the faculty, using 24-inch monitors and stereo compatible headphones. All apparatus was identical in terms of hardware and software. Students participated in the sessions in groups of 3 to 16. All participants were randomly assigned to the groups by randomly delivering the study materials using local area network via LanSchool software. Participants were positioned in a way that they would not be influenced from each other. Adhering to the ethical concerns, researchers informed participants about the process and voluntariness of the procedure, emphasizing that they could quit the experiment whenever they wanted without explanation. After the information phase, consent forms, pre-knowledge test and subject interest scales were delivered and participants were told to watch the animation only once wearing headphones. Sound levels were adjusted by the researchers before the study process. After studying on the animation, participants were told to fill the form including emotional experience questions, cognitive load scale, subject interest scale, motivation scale, and retention and transfer questions.

\section{Findings}

Data gathered from 256 participants were investigated on the basis of emotional design formats through descriptive statistics and comparison tests. Table 1 shows the number of participants for each group.

Table 1. Number of participants in control and treatment groups

\begin{tabular}{lll}
\hline Groups & n \\
\hline (C) & Basic multimedia design (BMD) & 45 \\
(T1) & Basic emotional design (BED) & 49 \\
(T2) & Emotional design with enhanced visual forms (ED-EV) & 47 \\
(T3) & Emotional design with character animations (ED-CA) & 59 \\
(T4) & Emotional design with character animations and sound effects (ED-CASE) & 56 \\
\hline
\end{tabular}

C: Control group; T1, T2, T3, T4: Treatment groups.

Descriptive statistics showed that dataset satisfied parametric test premises for all dependent variables while it failed to satisfy premises of multivariate analysis. So, each dependent variable was separately analyzed through variance analysis. Skewness and Kurtosis values 
were between -1 and +1 for all dependent variables, and histograms and box and plot graphics revealed normal distribution. As the interest is considered as an important mediator of motivation, it was used as a covariant variable while testing the effect of emotional design on motivation, and also based on correlation analysis showing significant correlation between pre-test score of subject interest and intrinsic motivation level $(r=0.59, \mathrm{p}<0.01)$.

In order to understand the emotional value of the animations, so as to be able to talk about emotional design effect, descriptive statistic and comparison tests results were interpreted. The eleven level Likert type question on emotional experience included negative experiences (from 1 to 5), neutral (6) and positive experiences (from 7 to 11). Descriptive statistics on emotional experience were given in Table 2.

Table 2. Descriptive statistics of emotional experience points

\begin{tabular}{lllllllll}
\hline Group & $\mathbf{n}$ & $\overline{\mathbf{x}}$ & Min & Max & Sd & \% (negative) & \% (neutral) & \% (positive) \\
\hline BMD & 45 & 6.80 & 4.00 & 10.00 & 1.49 & 15.6 & 31.1 & 53.3 \\
BED & 49 & 7.31 & 2.00 & 10.00 & 1.76 & 10.1 & 24.5 & 65.4 \\
ED-EV & 47 & 7.66 & 2.00 & 11.00 & 2.05 & 10.7 & 17.0 & 72.3 \\
ED-CA & 59 & 8.14 & 3.00 & 11.00 & 1.97 & 11.9 & 10.2 & 77.9 \\
ED-CASE & 56 & 8.84 & 2.00 & 11.00 & 1.89 & 5.4 & 7.1 & 87.5 \\
\hline
\end{tabular}

Descriptive statistics showed that mean scores for each group were above the mid-point $(\overline{\mathrm{x}}>$ 6.00), which indicated a positive emotional experience for all groups. However, it is clearly seen at Table 2 that mean scores gradually increased as the emotional elements used in animations were enhanced. What is more, frequency percentages, which were grouped as negative for ratings below 6.00, neutral for rating 6.00 and positive for ratings above 6.00, revealed higher percentages of positive experiences and lower percentages of negative and neutral experiences as the degree of emotional elements used in the animations got higher. In order to investigate whether the emotional experiences significantly differed by groups, a oneway ANOVA was conducted. Analysis of variance results showed a statistically significant difference $(\mathrm{F}=9.14, \mathrm{p}<0.001)$. Post-hoc tests revealed that ED-CASE group significantly reported higher ratings than BMD $(\mathrm{p}<0.001)$, BED $(\mathrm{p}<0.01)$ and $\mathrm{ED}-\mathrm{EV}(\mathrm{p}<0.05)$ groups while ED-CA group's were higher than those of BMD group $(p<0.01)$. According to these findings, it can be said that the animations affected the participants emotionally in the desired manner and ED-CASE and ED-CA animation formats were emotionally the most successful designs.

In order to investigate the effect of emotional design on learning, retention test scores and transfer test scores were separately subjected to one-way ANOVA, as the dataset did not satisfy multivariate analysis. Test results showed no significant difference for retention test scores $(\mathrm{F}=0.397, \mathrm{p}>0.05)$ while a significant difference was found for transfer test scores $(\mathrm{F}=5.31, \mathrm{p}<0.001)$. Post-hoc tests revealed that transfer test scores of ED-CASE and ED-CA groups were significantly higher than BMD group $(\mathrm{p}<0.01)$.

emotional design effect on intrinsic motivation was tested with one-way ANCOVA, subject interest pre-test scores being determined as covariant. ANCOVA results revealed a significant difference $(\mathrm{F}=6.81, \mathrm{p}<0.001)$. According to the post-hoc tests, ED-CASE, ED-CA and EDEV groups had significantly higher intrinsic motivation levels than BMD group $(p<0.001$; p <0.05; $\mathrm{p}<0.05)$, and ED-CASE group had significantly higher intrinsic motivation levels than BED group $(\mathrm{p}<0.01)$, which indicates the motivational enhancement of emotional designs. 
One-way ANOVA results showed no significant difference on subjective cognitive load scores $(\mathrm{F}=0.67, \mathrm{p}>0.05)$. Although this subjective measure does have various limitations, after interpreting this result along with the variance analysis results of retention and transfer test scores, it is still considered to be reliable.

Lastly, in order to understand whether different emotional design formats had an effect on subject interest, pre-test and post-test scores of subject interests were exposed to pairedsamples t-test. Significance level was identified as 0.01 because of Bonferroni adjustment. Paired-samples t-test results revealed that subject interest levels increased for only ED-CASE group $(\mathrm{t}=2.75, \mathrm{p}<0.01)$, while there were no statistically significant differences identified between the pre-test and post-test scores the other groups.

\section{Discussion, Results and Suggestions}

The findings of this study, on the whole, came up consistently with the predictions of CATLM, revealed that emotional design did have effects on educational variables, such as interest, motivation and meaningful learning, though not imposing an extraneous cognitive load as suggested by CTML. Besides, certain emotional designs were found to be more successful than others on the basis of emotional induction and accordingly on motivation, interest and learning.

\section{Evidence on Emotion Induction}

In this study, four different emotional multimedia designs were introduced and only two of them, which were designed with an artistic perspective focusing on emotional transfer, were considered to be emotionally effective on the participants. On the other hand, the design formats, which are considered to be unsuccessful on the emotional base, were the ones designed with the basic so-called emotional design elements, which were suggested in the multimedia learning literature, to be specific, the ones that adopt the use of appealing colors, rounded shapes and basic personification. Previous studies questioning the affective influence of emotional design were inconsistent considering the affective outcomes of the designs. While Um et al. (2011) reported that emotional design was effective on retaining positive mood, in a replication of this study, Plass et al. (2014) found inconsistent findings in two experiments on this effect, and while in another replication of the study, Park et al. (2015) was not successful to prove this effect. Mayer and Estrella (2014) found no significant difference on the ratings of appeal and enjoyment of the lesson between control and emotional design groups. Similarly, Königschulte (2015) reported that emotional design had no effect on the attractiveness and stimulation according to user experiences. At this point, this study puts forward a discussion on what emotional design actually means for multimedia learning field. Is it only a random practice of using psychologically proven elements in multimedia designs? Or should the main concern be how to evoke emotions of learners to take full advantage of the power of affective issues?. Considering the proven effects of emotions on cognition, motivation and learning, the latter appears to be more plausible. In this direction, future studies are suggested to study the emotional effects of multimedia learning materials in detail.

\section{Evidence on Learning}

Um et al. (2011), Mayer and Estrella (2014) and Plass et al. (2014) reported that participants got higher retention scores in their studies while Park et al. (2015), Haaranen (2015) and Königschulte (2015) reported no significant difference between control design and emotional design. On the other hand, Um et al. (2011) and Mayer and Estrella (2014) found 
that emotional design groups were more successful in transfer tests, while other studies reported no difference (Königschulte, 2015; Park et al., 2015; Plass et al., 2014). This study was unable to prove the effect of emotional design on retention as none of the four emotional design groups differed in terms of retention. On the other hand, participants studying character animated emotional design formats with character animations, which were also found to be emotionally more effective than basic multimedia design format, were more successful in terms of transfer questions than basic multimedia design, or the so-called neutral design. According to these findings, this study predicts that emotional design might not have a statistically significant effect on retention while it fosters meaningful learning.

\section{Evidence on Motivation and Interest}

Um et al (2011), Plass et al. (2014) and Königschulte (2015) reported that emotional design was effective on learners' motivation. Similarly, Mayer and Estrella (2014), pointing to motivation, reported that participants studying emotional design were more eager to attend similar lessons. The results of the present study were consistent with these results. Participants studying three emotional design formats, which are designed using more appealing visuals and enhanced personification, reported higher levels of intrinsic motivation than those studying basic multimedia design format. Besides, participants who studied the emotional design format that included character animations together with sound effects also reported higher intrinsic motivation than those who were engaged in basic emotional design and emotional design with enhanced visuals, suggesting that character animations together with sound effects were more effective in fostering motivation than basically using colors, rounded shapes and simple personification. As it comes to interest, Park et al. (2015) examined the effect of emotional design on situational interest and was not able to find a significant difference between emotional and neutral designs. Somehow inconsistent with their study, findings of this research showed a significant increase in the subject interest of participants who studied emotional design with character animations and complementary sound effects. In this manner, this study reveals that emotional design might be effective on subject interest as well.

\section{Evidence on Cognitive Load}

The results of the previous research were mostly consistent with each other considering the effect of emotional design on cognitive load levels. In only one experiment of Mayer and Estrella (2014) it was found an increase in extraneous cognitive load for emotional design group while other experiments reported no significant difference on cognitive load (Mayer \& Estrella, 2014; Um vd., 2011; Plass vd., 2014; Park vd., 2015; Königschulte, 2015). The results of this study were also consistent with the previous research considering the cognitive load, showing that emotional design did not cause extraneous cognitive load. Using subjective one-question cognitive load measure is, however, a limitation of the study and results require careful interpretation.

Overall, this study reveals that emotional design has a positive effect on the desired educational outcomes. However, four different emotional design formats were tested within this study and the effect of the ones, which were basically designed using color, shape and simple personification as suggested by the previous research, were not proven to be effective to increase aforementioned educational outcomes and even to induce emotions. So, it is important to emphasize that future research needs to to concentrate upon whether multimedia learning materials used are efficient to induce emotions, in order to be actually speaking of the effect of emotions. Besides, subjective measures were used in this study and future studies 
with physical measures should reveal deeper understanding about emotional experiences of individuals who study multimedia learning materials. Practical recommendation of this study would be for instructional material designers and developers, who should benefit from the potential of emotional elements that are reported in this study -of course, avoiding excessive use of them, which might, as well, cause extraneous cognitive load.

\section{Note}

This article was generated from the doctoral thesis of the authors, which was supported by Anadolu University Scientific Research Projects. Project No: 1609E615

\section{References}

Arnold, M. B. (1960). Emotion and Personality. New York: Columbia University Press.

Bülbül, A. H. \& Kuzu, A. (2019). On the track of emotional issues in the design of multimedia learning materials: A qualitative approach. Turkish Online Journal of Qualitative Inquiry, 10(1), 112-140.

Darwin, C. (2017). On the Origin of Species (B. Kılıç, Trans.). İstanbul: Alfa.

Eyler, J. \& Giles Jr, D. E. (1999). Where's the Learning in Service-Learning? Jossey-Bass Higher and Adult Education Series. San Francisco, CA: Jossey-Bass.

Felten, P., Gilchrist, L. Z., \& Darby, A. (2006). Emotion and learning: Feeling our way toward a new theory of reflection in service-learning. Michigan Journal of Community Service Learning, 12(2).

Fraenkel, J. R., Wallen, N. E., \& Hyun, H. H. (2012). How to Design and Evaluate Research in Education. New York: McGraw-Hill.

Haaranen, L., Ihantola, P., Sorva, J., \& Vihavainen, A. (2015, May). In search of the emotional design effect in programming. In 2015 IEEE/ACM 37th IEEE International Conference on Software Engineering Vol. 2 (pp. 428-434). IEEE.

Hertel, G., Neuhof, J., Theuer, T., \& Kerr, N. L. (2000). Mood effects on cooperation in small groups: Does positive mood simply lead to more cooperation?. Cognition \& emotion, 14(4), 441-472.

Isen, A. M. \& Reeve, J. (2005). The influence of positive affect on intrinsic and extrinsic motivation: Facilitating enjoyment of play, responsible work behavior, and selfcontrol. Motivation and Emotion, 29(4), 295-323.

Kılıç, E. \& Karadeniz, Ş. (2004). Hiper ortamlarda öğrencilerin bilişsel yüklenme ve kaybolma düzeylerinin belirlenmesi [Determining the cognitive load and disorientation level of the students on hypermedia environments]. Education Science: Theory and Practice, 10(4), 562-579.

Kim, C. \& Hodges, C. B. (2012). Effects of an emotion control treatment on academic emotions, motivation and achievement in an online mathematics course. Instructional Science, 40(1), 173-192.

Kolb, D. A. (1984). Experiential learning: Experience as the Source of Learning and Development. Englewood Cliffs, NJ: Prentice-Hall.

Königschulte, A. (2015). Sound as affective design feature in multimedia learning--Benefits and drawbacks from a cognitive load theory perspective. In 12th International Conference on Cognition and Exploratory Learning in Digital Age (pp. 7583).International Association for Development of the Information Society.

Magner, U. I. E., Schwonke, R., Aleven, V., Popescu, O., \& Renkl, A. (2013). Triggering situational interest by decorative illustrations both fosters and hinders learning in computer-based learning environments. Learning and Instruction, 29, 141-152. 
Mayer, R. E. (2009). Multimedia Learning Second Edition. New York, NY: Cambridge University Press.

Mayer, R. E. \& Estrella, G. (2014). Benefits of emotional design in multimedia instruction. Learning and Instruction, 33, 12-18.

Moreno, R. (2006). Does the modality principle hold for different media? A test of the method-affects-learning hypothesis. Journal of Computer Assisted Learning, 22(3), 149-158.

Paas, F. G. \& Van Merriënboer, J. J. (1993). The efficiency of instructional conditions: An approach to combine mental effort and performance measures. Human Factors: The Journal of the Human Factors and Ergonomics Society, 35(4), 737-743.

Park, B., Knörzer, L., Plass, J. L., \& Brünken, R. (2015). Emotional design and positive emotions in multimedia learning: An eyetracking study on the use of anthropomorphisms. Computers \& Education, 86, 30-42.

Pekrun, R. (1992). The impact of emotions on learning and achievement: Towards a theory of cognitive/motivational mediators. Applied Psychology, 41(4), 359-376.

Plass, J. L., Heidig, S., Hayward, E. O., Homer, B. D., \& Um, E. (2014). Emotional design in multimedia learning: Effects of shape and color on affect and learning. Learning and Instruction, 29, 128-140.

Rider, S. \& Peters, M. A. (2018). Post-truth, fake news: Viral modernity and higher education. In M. A. Peters, S. Rider, M. Hyvönen, \& T. Besley (Eds.), Post-truth, fake news: Viral modernity and higher education (pp. 3-12). Singapore: Springer.

Sansone, C. \& Harackiewicz, J. (2000). Looking beyond rewards: The problem and promise of intrinsic motivation. In C. Sansone \& J. Harackiewicz (Eds.) Intrinsic and Extrinsic Motivation (pp. 1-9). San Diego: Academic Press.

Schaffner, E. \& Schiefele, U. (2007). The effect of experimental manipulation of student motivation on the situational representation of text. Learning and Instruction, 17(6), 755-772.

Schunk, D. H., Meece, J. L., \& Pintrich, P. R. (2014). Motivation in Education: Theory, Research, and Applications (4th ed.). Boston, MA: Pearson.

Stein, N. \& Levine, L. (1991). Making sense out of emotion. In A. O. W. Kessen \& F. Kraik (Eds.), Memories Thoughts and Emotions: Essays in Honor of George Mandler (p. 295-322). Hillsdale: Erlbaum.

Sweller, J. (2005). Implications of cognitive load theory for multimedia learning. In R. E. Mayer (Ed.), The Cambridge Handbook of Multimedia Learning, 19-30. New York: Cmabridge University Press.

Thomas, F. \& Johnston, O. (1981). The Illusion of Life: Disney Animation. New York: Walt Disney.

Um, E., Plass, J. L., Hayward, E. O., \& Homer, B. D. (2012). Emotional design in multimedia learning. Journal of Educational Psychology, 104(2), 485. 